\title{
Organisational-based self-esteem: A within country comparison of outcomes between Māori and New Zealand Europeans
}

\author{
JARROD M. HAAR AND DAVID BROUGHAM ${ }^{*}$
}

\begin{abstract}
The present study investigates the influence of cultural differences on organisational-based self-esteem within New Zealand. A sample of 211 New Zealand European employees and 291 Māori (indigenous people of New Zealand) employees answered a range of questions on organisational-based self-esteem, job, and mood outcomes. Findings suggest that organisationalbased self-esteem was directly associated with job satisfaction, organisational commitment, and organisational citizenship behaviours, as well as positive and negative affect. Relationships between variables were tested for each sample separately and for a combined sample. A comparison between the separate and combined samples was also investigated. The findings from this study suggest that organisational-based self-esteem has a greater influence on job outcomes and mood outcomes for Māori when compared with New Zealand Europeans. This could be because employment fulfils a basic need for self-determination. The present study suggests the implementation of tailored management policies to support cultural differences within New Zealand's vibrant and diverse workforce.
\end{abstract}

Keywords: organisational-based self-esteem, within-country comparison, Māori,

New Zealand

Received 25 May 2015. Accepted 23 November 2015

\section{INTRODUCTION}

7 he present study investigates the influence of cultural differences on organisational-based self-esteem 1 (OBSE) within New Zealand. This paper defines and reviews the literature on OBSE that forms the independent variable in our study, and discusses how this might be applicable within the New Zealand context. The differences between New Zealand European and Māori (the indigenous people of New Zealand) culture are discussed through an individualism/collectivism lens. The literature review then focuses on hypothesis development, whereby OBSE will be used to predict a well-established set of job outcomes (i.e., job satisfaction, organisational commitment, organisational citizenship behaviours $[\mathrm{OCB}]$ ) and mood outcomes (i.e., positive affect and negative affect), which are the dependent variables within this study.

It is widely accepted that people who have high OBSE believe they are valued as members of an organisation and that self-esteem shapes employee attitudes, motivations, and behaviours (Chan, Huang, Snape, \& Lam, 2013; Ferris, Lian, Brown, \& Morrison, 2015). However, Pierce and Gardners

* Department of Management, Auckland University of Technology, Auckland, New Zealand

** School of Management, College of Business (Palmerston North), Massey University, New Zealand

Corresponding author: d.brougham@massey.ac.nz 
(2004) raised a number of issues relating to the understanding of this concept and, in particular, raised a major measurement issue regarding the need for wider international settings for OBSE studies. OBSE studies have, to date, been undertaken at a country level within North America, the Middle East, Asia, and Europe (Pierce, Gardner, Cummings, \& Dunham, 1989; Aryee \& Luk, 1996; Tang \& Ibrahim, 1998; Tang et al., 2002; Chen, Aryee, \& Lee, 2005; Lapointe, Vandenberghe, \& Panaccio, 2011; Chan et al., 2013; Liu, Hui, Lee, \& Chen, 2013). There is a need to expand our understanding of how this construct differs within countries. Although some researchers continue to focus on workplace and well-being outcomes at a national level (Hofstede, 1980; Spector et al., 2004; Spector et al., 2007), there has been a paradigm shift within cross-cultural literature, moving the focus to cultural differences within countries (Cohen, 2007; Hofstede, Garibaldi de Hilal, Malvezzi, Tanure, \& Vinken, 2010). These findings show that cultural differences within a country can result in similar levels of variance to those produced in studies comparing variances at a national level between countries. This method of investigation is still under-researched and merits more attention in management literature. While OBSE studies seek to advance the knowledge in this area, to the best of our knowledge, no OBSE study has focused on the potentially vast cultural differences within a country.

Pierce et al. described self-esteem as an 'attitude of approval or disapproval of self; it is a personal evaluation reflecting what people think of themselves as individuals; it indicates the extent to which individuals believe themselves to be capable, reflecting a personal judgment of worthiness' (1989: 625). OBSE is defined as 'the degree to which organizational members believe that they can satisfy their needs by participating in roles within the context of an organization' (Pierce et al., 1989: 625). While general self-esteem constructs provide a platform for predicting general life outcomes, it is widely accepted that more focused forms of self-esteem, such as OBSE, enable researchers to predict specific outcomes (i.e., workplace outcomes) with greater certainty (Pierce et al., 1989). This was highlighted by a meta-analysis conducted by Bowling, Eschleman, Wang, Kirkendall, and Alarcon, who found that 'OBSE generally yielded stronger relationships with work-related variables than does general self-esteem' (2010: 618). OBSE is considered to be one of the lower-order dimensions of general self-esteem (Bowling et al., 2010) and is used to explain the effects of self-esteem on organisational variables.

Focusing on OSBE within countries is particularly important to countries that are ethnically diverse and those that may become more diverse over time. New Zealand offers a unique research setting because of its bicultural identity and multicultural society. The present study tests the OBSE of New Zealand Europeans (the majority) and of Māori (the indigenous people of New Zealand). In general, these two ethnic groups hold significantly different cultural worldviews (Durie, 2003; King, 2003; Hook, 2007). While Māori culture is difficult to pin down, it is considered to be more collectivistic than New Zealand European (Hook, 2007; Podsiadlowski \& Fox, 2011). While Māori have a Polynesian ancestry, the passage of time and the extended exposure to European culture restrict our understanding of contemporary Māori culture. Accordingly, this study relies on a broad and established cultural value, individualism/collectivism, to illustrate these cultural differences between Māori and New Zealand Europeans. Using collectivism exclusively to focus on these differences in culture within New Zealand has been used by Podsiadlowski and Fox (2011).

These levels of higher collectivism have been tested empirically by Harrington and Liu (2002) and Tassell, Flett, and Gavala (2010). Both these papers discussed the importance of broader social connections for Māori, that is, whānau (extended family), and the connection to iwi (tribes) and hapu (sub tribes). New Zealand's European culture, equally if not harder to pin down, draws influence from a British background (Lo \& Houkamau, 2012). In general, they tend to be more individualistic, caring more about self and immediate family (Hook, 2007). However, it must be noted that Māori and New Zealand Europeans have affected each other's cultures profoundly since (King, 2003; Podsiadlowski \& Fox, 2011). This effect is still ongoing and dynamic. 
We argue that these cultural differences within New Zealand are likely to affect various workplace outcomes. For example, how an individual considers the in-group rather than oneself, as well as views on social norms, duty, cooperation, and sharing, have a profound effect on how they carry out their job in the workplace (Wheeler, Reis, \& Bond, 1989; Ramamoorthy \& Carroll, 1998). These points will be elaborated on within the literature review. As such, this paper seeks to highlight how OBSE differs between these two groups. This research makes three contributions to the literature: (1) it adds to the globalisation of OBSE through its New Zealand setting and, importantly, through its testing of OBSE's effects on indigenous peoples, a focus that is severely lacking (Brougham \& Haar, 2013; Haar \& Brougham, 2013); (2) it conducts a within-country test of OBSE by comparing its influence on outcomes between the majority ethnic group (New Zealand European; hereafter European) and the indigenous population (Māori), both individually and combined; and (3) it extends the literature by testing for mood outcomes, which have been under explored.

\section{LITERATURE REVIEW}

It has been suggested that people who have high OBSE believe they are valued members of an organisation and perceive that, as employees, they are important, meaningful, effectual and worthwhile within their organization' (Pierce et al., 1989: 625). Pierce et al. commented on this finding, stating that 'experiences within an organization will shape OBSE, which will also affect organization-related behaviors and attitudes' (1989: 626). A meta-analysis conducted by Bowling et al. (2010) highlighted many of the predictors of OBSE, which included job complexity; autonomy; and supervisor, coworker, and organisational support. These authors also highlighted the importance of role ambiguity, conflict, overload, and job insecurity. Overall, research has concluded that OBSE shapes employee attitudes, motivations, and behaviours. Employees' levels of OBSE are potentially changeable; therefore, these findings may help organisations to identify those antecedents to OBSE that could benefit from adjustment. Such adjustments may, subsequently, help to improve both employee behaviour and motivations, and, as an effect of this improvement, organisational outcomes (Pierce \& Gardner, 2004).

\section{OBSE outcomes}

Researchers have drawn main effect links between OBSE and a number of favourable work outcomes, such as career satisfaction (Judge \& Bono, 2001; Van Dyne \& Pierce, 2004), turnover intentions (Gardner \& Pierce, 2001; Riordan, Weatherly, Vandenberg, \& Self, 2001; Lapointe, Vandenberghe, \& Panaccio, 2011), and job performance (Gardner, Van Dyne, \& Pierce, 2004; Chen, Aryee, \& Lee, 2005; Liu et al., 2013). These significant relationships between OBSE and favourable work outcomes suggest that employees with high OBSE 'engage in behaviours valued in their organization' (Pierce et al., 1989: 630). Our analysis also highlighted the power of OBSE as a predictor of job outcomes over general self-esteem (Bowling et al., 2010).

Our current study focuses on three work outcomes: (1) job satisfaction, (2) organisational commitment, and (3) OCBs. The first two outcomes were chosen because they receive the bulk of research attention (Pierce \& Gardner, 2004) and, therefore, allow us to compare those effects on Māori employees to established outcomes. Given the importance of employee studies of job performance, we added OCBs to extend this field of research.

\section{Job satisfaction}

In Judge and Bono's (2001) meta-analysis, the strongest correlation identified with job satisfaction was self-esteem. This finding supports Pierce et al.'s, 1989 study, which reported on four different samples 
and found that OBSE correlated with job satisfaction and accounted for large amounts of variance. A large number of studies have confirmed Pierce et al.'s findings by proving the links between OBSE and job satisfaction (e.g., Van Dyne \& Pierce, 2004) and showing that a positive relationship exists between OBSE and various facets of job satisfaction. In their review of the literature, Pierce and Gardner stated 'the correlation between OBSE and job satisfaction is a robust and substantial one ranging between .23 and .70' (2004: 606).

\section{Organisational commitment}

The links between OBSE and organisational commitment are well established (Lapointe, Vandenberghe, \& Panaccio, 2011), with Pierce and Gardner stating that the literature shows 'a significant and positive relationship between OBSE and commitment (with correlations ranging between .12 and .64)' (2004: 606). In their study of multiple employee groups, Pierce et al. (1989) found OBSE correlated with organisational commitment and accounted for large amounts of variance amongst teachers, mining employees, school district employees, automobile service-club employees, and education association employees, ranging from .43 to .60 (all $p<.01$ ). Overall, there is evidence that 'employees with high levels of self-esteem are more committed to their organizations than their low self-esteem counterparts' (Pierce \& Gardner, 2004: 606).

\section{OCBs}

OCBs are individuals' discretionary behaviours that are not recognised by formal rewards but help organisations function effectively (Organ, 1988). They include actions such as helping others or preventing work-related problems (Podsakoff, MacKenzie, Paine, \& Bachrach, 2000). Smith, Organ, and Near recognized that OCBs are important to organisations as they 'lubricate the social machinery of the organization' (1983: 654). Podsakoff et al. (2000) noted that OCBs enhance employee and managerial productivity, reducing the need to use resources for social maintenance functions. OCBs have been explored within OBSE literature, although some dimensions have received more attention than others (Pierce \& Gardner, 2004). Tang and Ibrahim stated that 'employees with a high OBSE tend to be better organizational citizens' (1998: 532), and Van Dyne and Pierce state that 'when employees feel that the organization contributes to their basic needs, they reciprocate by making positive, proactive contributions to the organization' (2004: 446). Conversely, employees with low self-esteem will normally refrain from OCBs (Ferris et al., 2015). These studies are endorsed by Bowling et al.'s (2010) study, where support for OBSE as a predictor of job satisfaction, organisational commitment, and OCBs was found. This leads to our first set of hypotheses.

Hypotheses: High OBSE will be positively related to (1) job satisfaction, (2) organisational commitment, and (3) OCBs.

\section{Moods}

The examination of moods in OBSE research is limited (Bowling et al., 2010). Price (1997) noted that positive affectivity and negative affectivity refer to the tendency to experience pleasant and unpleasant emotions, respectively. Watson and Clarke (1988) characterised negative affectivity as being related to individuals experiencing high levels of anxiety, and often depression, while positive affectivity reflects enthusiasm, the enjoyment of life, and being mentally alert. Affectivity is not a continuum: people can have degrees of both positive and negative affectivity (Price, 1997), and thus they are distinct variables (Warr, Barter, \& Brownbridge, 1983). Pierce and Gardner (2004) have noted that although studies 
which look at both OBSE and affectivity are sparse, there is evidence that they are related (Lee, 2003; Heck, Bedeian, \& Day, 2005). We follow Pierce and Gardner's (2004) suggestion that OBSE will influence dispositional states such as affectivity. While many studies have found that high levels of OBSE lead to positive work attitudes, we suggest that high OBSE will lead employees to report higher positive affectivity and lower negative affectivity. This leads to our second set of hypotheses.

Hypotheses: High OBSE will be (4) positively related to positive affectivity and (5) negatively related to negative affectivity.

\section{Within-country differences}

Pierce and Gardner stated that, while OBSE research has been undertaken in over a dozen countries, it is not known to what extent culture is a boundary condition. It is possible that people from collectivistic cultures may think of self (e.g., I COUNT around here) differently from those with more individualistic values' (2004: 597). This relates to Riordan and Vandenberg's (1994) assertion that OBSE, which focuses on the individual (e.g., 'I count around here'), might be harder for employees from collectivistic cultures to grasp because of the focus on the individual rather than the group. An interesting discussion around boundary conditions was conducted by Lee, Chiu, and Chan, who found that, 'there is no clear evidence for higher recognition rates when the expressors are Japanese than when they are Americans' (2005: 240) when trying to decode facial emotions, highlighting the lack of in-group advantage. This contradicted previous research by Elfenbein and Ambady (2002), who found that the same cultural group could more accurately recognise emotions of their peers. These research findings would have differing implications within a multicultural country as identification of cultural nuances can be developed over time.

Sedikides, Gaertner, and Toguchi (2003) noted that further research needs to be undertaken to identify how national cultures affect the operation of OBSE. Despite these limitations, empirical evidence has supported OBSE in nonWestern settings. Tang and Ibrahim (1998) found OBSE to be a consistent predictor of altruism and compliance in both US and Middle Eastern settings, indicating its ability to predict outcomes amongst individualistic and collectivistic employees. New Zealand is similar to other Western countries in that it has a majority European population while also boasting a large number of minority groups. The most recent census data from Statistics New Zealand (2013a) shows that Māori make up $14.9 \%$ of the population compared with $74.0 \%$ European. Māori, compared with Europeans, underperform in the workforce and have significantly higher unemployment $-14.1 \%$ compared to 5.3\% (Statistics New Zealand, 2013b) - and lower incomes (Statistics New Zealand, 2007). Furthermore, Māori occupy a greater proportion of unskilled positions, although this trend appears to be reversing (Te Puni Kōkiri, 2009, 2012). These factors are important as they may result in OBSE having an increased significance for Māori employees compared with European employees.

Early research by Hofstede (1980) popularised the study of culture by comparing countries through sets of fixed measures. However, Cohen warned that within countries 'several different cultures can exist together, each with its own norms, religion, language, and way of life. Combining all of them into one group might result in a faulty representation of the nature of the culture of a given country' (2007: 274). Hofstede acknowledged limitations in his approach, noting that there are significant cultural differences within national contexts, which may lead researchers to make 'statements about national culture or national character smell of superficiality and false generalization' (1983: 77).

Studies have found significant ethnic differences within countries when researching organisational commitment (Cohen, 1999), work demands, turnover, and absenteeism (Cohen \& Kirchmeyer, 2005), and OCBs (Cohen, 2006). Cohen (2007) focused on five groups of teachers representing different cultural groups within Israel and found significant differences between the five groups, leading 
the author to state 'one can argue that differences between ethnic or cultural groups might be stronger than differences between countries' (Cohen, 2007). These within-country effects have also been found in Brazil (Hofstede et al., 2010), indicating that these differences may also be found outside Israel.

This paper responds to calls from Erez and Gati (2004), who appealed for a paradigm shift when researching culture and suggested that culture is dynamic and multifaceted within each country. Cohen stated that 'culture is much more than the difference between one country and another ... researchers should therefore be cautious in comparing countries without a more detailed description of their sample in terms of potential cultural differences within it' (2006: 115). Cohen and Kirchmeyer's (2005) results show the importance of exploring within-country differences separately. Although their overall model found that absenteeism frequency accounted for $31 \%$ variance (all groups combined), extremes were found when participants were separated out into racial groups, with variance ranging from 4 to 47\%: thus, the former model had no significant predictors. It follows, therefore, that combining different ethnic groups may mask underlying patterns and effects. However, these withincountry differences are not always significant, and might provide contradictory results. For example, Mueller, Finley, Iverson, and Price (1999) tested white and African-American teachers in the United States, and found no significant between-race differences (although whites had higher career commitment), but significant differences towards outcomes.

The present study extends this approach to explore differences in the effectiveness of OBSE in predicting outcomes for Europeans and Māori. We explore New Zealand because it is an advanced country with a stable economy and social structure. Comparing the majority (European) with the minority (Māori) may also be of relevance to countries such as the United States where AfricanAmericans, Latinos, and Asians make up sizeable minority groups. Despite the potential for increased benefits, OBSE among Māori employees may be lower because of comparatively poorer pay and opportunities for promotion (Te Puni Kōkiri, 2012). However, based on the findings of Mueller et al. (1999), we suggest that Māori employees will have similar levels of OBSE as European employees, but that they will be more likely to appreciate the benefits of OBSE, and that OBSE will have a greater influence on their work and mood outcomes. We suggest that employment can have a greater effect on Māori OBSE due to the importance in shaping their self-determination (Durie, 2003). Furthermore, Te Puni Kōkiri (2012) suggested that employment opportunities have a significantly positive effect on prosperity, well-being, and engagement for Māori.

Following Cohen and Kirchmeyer (2005), we posit that the benefits of OBSE will be greater for Māori than for Europeans. We suggest that Māori employees, while having similar levels of OBSE to European employees, will have greater work outcomes and better moods because they will have an appreciation and respect for work and its accompanying self-esteem. For example, while two employees (one Māori and one European) might have similar levels of OBSE, the Māori employee will feel greater commitment and satisfaction in their job, and be more positive in their mood. This is because they are enlivened and energised by the benefits of their self-esteem being built by their organisational experiences. This notion was suggested by Hartung, Fouad, Leong, and Hardin, who discussed the likelihood of collectivists being similar in 'individualists to align their occupational choices and plans with their own personal goals and aspirations' (2010: 40). We argue that employment and utilisation of one's skills might not only lead to OBSE, but also have a greater influence on outcomes because of the important achievement of fulfilling meaningful employment in a national setting where the indigenous population is often underutilised in the workforce (Haar \& Brougham, 2011; Te Puni Kōkiri, 2012). This leads to our last set of hypotheses.

Hypothesis 6: Māori employees will report levels of OBSE similar to European employees.

Hypothesis 7: The influence of OBSE towards work and mood outcomes will be higher for Māori employees than for European employees. 


\section{METHOD}

Approximately 250 organisations from throughout New Zealand were approached and had the study and its requirements explained to them. We selected organisations with a large proportion of Māori workers. Employees were told that the survey was limited to employees who identify as either European or Māori. Although these cultural classifications are board, they fall in line with the Statistics New Zealand cultural classifications. Approximately 1,200 surveys were distributed, although the specific ethnic breakdown of initial survey participants was not known. For all participants, data collection was undertaken in two waves, with a 1-month gap between surveys to eliminate issues relating to common-method variance. Surveys were matched by a unique employee code. Survey one contained the measures for OBSE as well as demographic variables; survey two contained the outcomes variables. In total, 502 employees responded to both surveys, representing a $41.8 \%$ response rate. The final breakdown was 211 European and 291 Māori.

On average, participants were 39.0 years old $(\mathrm{SD}=12.6$ years), parents $(66 \%)$, married $(65 \%)$, and female $(55 \%)$. Participants worked $40.6 \mathrm{hr} /$ week $(\mathrm{SD}=11.8 \mathrm{hr})$ and had job tenure of 7.9 years $(\mathrm{SD}=9.0$ years). Education levels were diverse, with $26.9 \%$ holding a high school qualification, $21.2 \%$ a technical college qualification, $35 \%$ a university degree, and $16.8 \%$ a postgraduate qualification. By industry sector, $51.4 \%$ worked in the public sector, $41.5 \%$ in the private sector, and $7.1 \%$ in the not-for-profit sector.

\section{Measures}

OBSE was measured using the 10-item measure by Pierce et al. (1989). OBSE was coded $1=$ 'strongly disagree', to $5=$ 'strongly agree'. The items followed the stem 'Around here $\ldots$ ' and sample items were 'I am taken seriously', and 'I am trusted'. The Cronbach's $\alpha$ were $\alpha=0.93$ for all three samples (combined, European, and Māori).

Job satisfaction was measured using 5 -items by Judge, Bono, Erez, and Locke (2005), coded $1=$ 'strongly disagree' to $5=$ 'strongly agree'. Respondents were asked to indicate how satisfied or unsatisfied they were with different features of their present job. A sample item was 'I find real enjoyment in my work'. The Cronbach's $\alpha$ for the three samples were: $\alpha=0.80$ (combined), $\alpha=0.84$ (European), and $\alpha=0.77$ (Māori). Organisational commitment was measured using the affective commitment subscale of Meyer, Allen, and Smith (1993), coded 1 = 'strongly disagree', to $5=$ 'strongly agree'. A sample item was 'I would be very happy to spend the rest of my career with this organization'. The Cronbach's $\alpha$ for the three samples were: $\alpha=0.78$ (combined), $\alpha=0.80$ (European), and $\alpha=0.75$ (Māori).

OCBs were measured using 8-items from Lee and Allen (2002) using the organisation dimension. Sample items were 'Attend functions that are not required but that help the organizational image' and 'Offer ideas to improve the functioning of the organization', coded $1=$ 'never', to $5=$ 'always'. The Cronbach's $\alpha$ for the three samples were: $\alpha=0.91$ (combined), $\alpha=0.89$ (European), and $\alpha=0.91$ (Māori). Moods were assessed using items from Watson, Clark, and Tellegen's (1988) Positive and Negative Affect Schedule, coded $1=$ 'very slightly', to $5=$ 'extremely'. A total of 10 items were used, with 5-items for positive affect (enthusiastic, interested, determined, excited, and inspired) and 5 -items for negative affect (upset, irritable, scared, ashamed, and jittery). The Cronbach's $\alpha$ for positive affect were $\alpha=0.90$ for all three samples and for negative affect were $\alpha=0.81$ for all three samples.

A number of variables were controlled, specifically age (in years); education ( $1=$ 'high school equivalent', 2 = 'professional qualification', 3 = 'bachelor degree', and 4 = 'postgraduate qualification'); tenure (in years); and hours worked (total hours per week). 


\section{Analysis}

Hierarchical regression analysis was used to analyse the data. In Step 1, control variables (age, education, tenure, and hours worked) were entered, with OBSE entered in Step 2. The regression model was run three times ( 1 = 'combined sample', 2 = 'European', 3 = 'Māori'), for each outcome (job satisfaction, organisational commitment, OCBs, positive affect, and negative affect). We conducted post-hoc power analysis to determine whether the sample size was adequate. Given our 1,200 population size, with a $5 \%$ error rate and 95\% confidence level, we would need a total (European and Maori) sample size of 292 (total) to achieve this. Our overall sample size was 502. As such, our post-hoc analysis suggests sufficient power in our data set.

\section{RESULTS}

Descriptive statistics for all the study variables are shown in Tables $1 \mathrm{a}$ and $1 \mathrm{~b}$.

From Table 1a it can be see that the overall mean score for OBSE is 4.1 (SD = 0.61), which is well above the mid-point of 3.0, indicating that participants in our sample had high levels of OBSE. Table $1 \mathrm{~b}$ shows that the OBSE scores for European $(\mathrm{M}=4.2)$ and Māori $(\mathrm{M}=4.1)$ are similar, and a $t$-test confirmed there was no significant difference $(t=-0.797, p=.426)$ : this supports Hypothesis 6 . Overall, OBSE is significantly correlated with job outcomes and affectivity outcomes in the expected directions for both the combined sample (Table 1a) and the separate samples (Table 1b). Of the control variables, only tenure is significantly correlated with OBSE and only for Māori employees $(r=0.15, p<.05)$.

Results of the hierarchical regressions for Hypotheses 1-5 are shown in Tables 2 and 3.

OBSE is significantly associated with job satisfaction in all samples: combined sample $(\beta=0.35$, $p<.001)$, European sample $(\beta=0.19, p<.05)$, and Māori sample $(\beta=0.46, p<.001)$. From the $R^{2}$ change figures in Step 2 , it can be seen that OBSE accounts for $12 \%$ of the total variance $(p<.001)$ for job satisfaction in the combined sample, only $3 \%(p<.05)$ in the European sample, and a much larger 21\% $(p<.001)$ in the Māori sample. Similarly, OBSE is significantly associated with organisational commitment in the combined sample $(\beta=0.36, p<.001)$, the European sample $(\beta=0.23, p<.01)$, and the Māori sample $(\beta=0.49, p<.001)$. From the $R^{2}$ change figures in Step 2 , it can be seen that OBSE accounts for $13 \%$ of the total variance $(p<.001)$ for organisational commitment in the combined sample, only $5 \%(p<.01)$ in the European sample, and a much larger $23 \%(p<.001)$ in the Māori sample. The effects of OBSE are also significantly associated with OCBs in the combined sample $(\beta=0.29, p<.001)$ and the Māori sample $(\beta=0.39, p<.001)$, but not in the European sample. From the $R^{2}$ change figures in Step 2, it can be seen that OBSE accounts for $8 \%$ of the total variance $(p<.001)$ for OCBs in the combined sample, but a nonsignificant $2 \%$ in the European sample and a larger $15 \%$ $(p<.001)$ in the Māori sample. Overall, there is support for OBSE influencing job outcomes, supporting Hypotheses 1-3.

Towards positive affectivity, OBSE is significant in all samples: combined $(\beta=.37, p<.001)$, European $(\beta=0.20, p<.05)$, and Māori $(\beta=0.47, p<.001)$. From the $R^{2}$ change figures in Step 2, it can be seen that OBSE accounts for $14 \%$ of the total variance $(p<.001)$ for positive affectivity in the combined sample, only $4 \%(p<.05)$ in the European sample, and a much larger $22 \%(p<.001)$ in the Māori sample. Similarly, OBSE is significantly associated with negative affectivity in all samples: combined $(\beta=-0.22, p<.001)$, European $(\beta=-0.25, p<.01)$, and Māori $(\beta=-0.21, p<.01)$. From the $R^{2}$ change figures in Step 2, it can be seen that OBSE accounts for a small $5 \%$ of the total variance $(\mathrm{p}<.001)$ for negative affect in the combined sample, with similar results for both the European $(6 \%, p<.01)$ and Māori samples $(4 \%, p<.001)$. Overall, there is support for OBSE influencing affectivity outcomes, supporting Hypotheses 4 and 5. 
Table 1. Descriptive statistics and correlations

\begin{tabular}{|c|c|c|c|c|c|c|c|c|c|c|c|c|c|c|}
\hline \multirow[b]{2}{*}{ Variables } & \multicolumn{2}{|c|}{ European } & \multicolumn{2}{|c|}{ Māori } & \multirow[b]{2}{*}{1} & \multirow[b]{2}{*}{2} & \multirow[b]{2}{*}{3} & \multirow[b]{2}{*}{4} & \multirow[b]{2}{*}{5} & \multirow[b]{2}{*}{6} & \multirow[b]{2}{*}{7} & \multirow[b]{2}{*}{8} & \multirow[b]{2}{*}{9} & \multirow[b]{2}{*}{10} \\
\hline & M & $S D$ & $M$ & $S D$ & & & & & & & & & & \\
\hline \multicolumn{15}{|l|}{ (a) Combined samples } \\
\hline 1. Age & 39.0 & 12.6 & & & - & & & & & & & & & \\
\hline 2. Education & 2.4 & 1.1 & & & $0.15^{\star \star}$ & - & & & & & & & & \\
\hline 3. Tenure & 7.9 & 9.0 & & & $0.49 * \star$ & -0.07 & - & & & & & & & \\
\hline 4. Hours worked & 40.7 & 11.8 & & & $0.27^{\star *}$ & 0.01 & $0.25^{\star \star}$ & - & & & & & & \\
\hline 5. Job satisfaction & 3.7 & 0.68 & & & $0.12^{\star \star}$ & 0.09 & $0.10^{\star}$ & $0.11^{\star}$ & - & & & & & \\
\hline 6. Organisational commitment & 3.3 & 0.73 & & & $0.17^{\star \star}$ & 0.05 & $0.24^{\star \star}$ & $0.15^{\star \star}$ & $0.59^{\star \star}$ & - & & & & \\
\hline 7. OCBs & 3.6 & 0.86 & & & $0.15^{\star \star}$ & 0.03 & $0.17^{\star \star}$ & $0.16^{\star \star}$ & 0.40 ** & $0.56^{\star \star}$ & - & & & \\
\hline 8. Positive affect & 3.7 & 0.82 & & & 0.06 & 0.01 & $0.15^{\star \star}$ & $0.15^{\star \star}$ & $0.48^{\star \star}$ & $0.38^{\star \star}$ & $0.37 * \star$ & - & & \\
\hline 9. Negative affect & 1.6 & 0.69 & & & $-0.10^{\star}$ & 0.01 & -0.08 & -0.06 & $-0.28^{\star \star}$ & $-0.24^{\star \star}$ & -0.09 & $-0.14^{\star \star}$ & - & \\
\hline 10. OBSE & 4.1 & 0.61 & & & -0.01 & -0.01 & 0.07 & 0.06 & $0.32^{\star *}$ & $0.36^{\star *}$ & $0.28^{\star *}$ & $0.35^{\star \star}$ & $-0.22^{\star \star}$ & - \\
\hline \multicolumn{15}{|c|}{ (b) Within-country racial groups } \\
\hline 1. Age & 38.8 & 13.5 & 39.1 & 12.0 & - & 0.10 & $0.42^{\star \star}$ & $0.23^{\star \star}$ & 0.03 & 0.10 & $0.21^{\star *}$ & 0.07 & -0.06 & 0.01 \\
\hline 2. Education & 2.1 & 1.0 & 2.7 & 1.0 & $0.23^{\star \star}$ & - & $-0.16^{\star}$ & -0.03 & 0.07 & 0.07 & 0.11 & -0.05 & 0.02 & -0.06 \\
\hline 3. Tenure & 10.6 & 10.4 & 6.0 & 7.1 & $0.59^{\star \star}$ & 0.14 & - & 0.26 ** & 0.04 & $0.13^{\star}$ & $0.17^{\star \star}$ & $0.17^{\star \star}$ & -0.03 & $0.15^{\star}$ \\
\hline 4. Hours worked & 41.0 & 13.7 & 40.4 & 10.2 & $0.32^{\star \star}$ & 0.06 & $0.23^{\star \star}$ & - & 0.02 & 0.07 & 0.12 & $0.21^{\star *}$ & -0.08 & 0.02 \\
\hline 5. Job satisfaction & 3.8 & 0.69 & 3.7 & 0.67 & $0.25^{\star \star}$ & $0.17^{\star}$ & 0.11 & $0.20 * \star$ & - & $0.53^{\star \star}$ & $0.35^{\star \star}$ & $0.51^{\star \star}$ & $-0.25^{\star \star}$ & $0.39 * \star$ \\
\hline 6. Organisational commitment & 3.5 & 0.73 & 3.2 & 0.69 & $0.29 * \star$ & $0.18^{\star}$ & $0.25^{\star \star}$ & $0.23^{\star *}$ & $0.65^{\star \star}$ & - & $0.50^{\star *}$ & $0.41^{\star *}$ & $-0.24^{\star \star}$ & $0.45^{\star \star}$ \\
\hline 7. OCBs & 3.8 & 0.74 & 3.4 & 0.89 & 0.09 & 0.07 & 0.06 & $0.22^{\star \star}$ & $0.47^{\star \star}$ & $0.60 * \star$ & - & $0.37^{\star \star}$ & -0.00 & $0.33^{\star *}$ \\
\hline 8. Positive affect & 3.7 & 0.76 & 3.6 & 0.86 & 0.06 & 0.12 & 0.12 & 0.08 & $0.45^{\star \star}$ & $0.34^{\star \star}$ & $0.38^{\star \star}$ & - & -0.10 & $0.45^{\star \star}$ \\
\hline 9. Negative affect & 1.5 & 0.60 & 1.7 & 0.74 & $-0.16^{*}$ & -0.08 & -0.08 & -0.03 & $-0.30^{\star \star}$ & $-0.20^{\star \star}$ & $-0.15^{\star}$ & $-0.20^{\star \star}$ & - & $-0.21^{\star \star}$ \\
\hline 10. OBSE & 4.2 & 0.59 & 4.1 & 0.62 & -0.03 & 0.09 & -0.01 & 0.10 & 0.21 ** & $0.25^{\star \star}$ & $0.19^{\star *}$ & $0.17^{\star}$ & $-0.25^{\star \star}$ & - \\
\hline
\end{tabular}

Notes. $N=502$ (European $=211$ and Māori = 291). Māori above diagonal.

OBSE $=$ organisational-based self-esteem; $\mathrm{OCBs}=$ organisational citizenship behaviours.

${ }^{*} p<.05 ;{ }^{* \star} p<.01$. 
Table 2. Regression coefficients for OBSE and job outcomes: Comparing Within-COUntry racial groups

\begin{tabular}{|c|c|c|c|c|c|c|c|c|c|}
\hline \multirow[b]{2}{*}{ Variables } & \multicolumn{3}{|c|}{ Job satisfaction } & \multicolumn{3}{|c|}{ Organisational commitment } & \multicolumn{3}{|c|}{ OCBs } \\
\hline & Combined & European & Māori & Combined & European & Māori & Combined & European & Māori \\
\hline \multicolumn{10}{|l|}{ Step 1: Controls } \\
\hline Age & 0.07 & 0.16 & 0.03 & 0.04 & 0.10 & 0.04 & 0.04 & 0.02 & 0.10 \\
\hline Education & 0.07 & 0.12 & 0.08 & 0.01 & 0.08 & 0.05 & -0.00 & 0.01 & 0.11 \\
\hline Tenure & 0.07 & 0.00 & 0.04 & $0.23 \ddagger$ & 0.18 & $0.16^{\star}$ & $0.15^{\star}$ & 0.01 & $0.18^{*}$ \\
\hline Hours worked & 0.06 & 0.10 & 0.02 & 0.07 & 0.10 & 0.05 & $0.12^{\star}$ & $0.17^{\star}$ & 0.09 \\
\hline$R^{2}$ change & $0.03^{*}$ & $0.07^{\star}$ & 0.01 & $0.08 \ddagger$ & $0.10^{\star \star}$ & 0.04 & $0.05 \ddagger$ & 0.04 & $0.08^{* *}$ \\
\hline \multicolumn{10}{|l|}{ Step 2: Predictor } \\
\hline OBSE & $0.35 \ddagger$ & $0.19 *$ & $0.46 \neq$ & $0.36 \ddagger$ & $0.23^{\star \star}$ & $0.49 \ddagger$ & $0.29 \ddagger$ & 0.13 & $0.39 \ddagger$ \\
\hline$R^{2}$ change & $0.12 \ddagger$ & $0.03^{\star}$ & $0.21 \ddagger$ & $0.13 \ddagger$ & $0.05^{\star \star}$ & $0.23 \ddagger$ & $0.08 \ddagger$ & 0.02 & $0.15 \ddagger$ \\
\hline Total $R^{2}$ & 0.15 & 0.10 & 0.22 & 0.21 & 0.15 & 0.27 & 0.14 & 0.05 & 0.23 \\
\hline Adjusted $R^{2}$ & 0.14 & 0.08 & 0.20 & 0.20 & 0.12 & 0.25 & 0.12 & 0.02 & 0.21 \\
\hline F statistic & $13.106 \ddagger$ & $3.689 * \star$ & 11.981‡ & $20.359 \ddagger$ & $5.635 \ddagger$ & $15.807 \ddagger$ & $12.072 \ddagger$ & 1.701 & 13.114† \\
\hline
\end{tabular}

Notes. Standardised regression coefficients, all significance tests were two-tailed.

OBSE = organisational-based self-esteem; OCBs = organisational citizenship behaviours.

${ }^{\star} p<.05 ;{ }^{\star \star} p<.01 ; \neq p<.001$.

TAble 3. Regression COEfFICIENTS For OBSE AND AFFECt OUtCOMES: COMPARING Within-COUNTRY RACIAL GROUPS

\begin{tabular}{|c|c|c|c|c|c|c|}
\hline \multirow[b]{2}{*}{ Variables } & \multicolumn{3}{|c|}{ Positive affect } & \multicolumn{3}{|c|}{ Negative affect } \\
\hline & Combined & European & Māori & Combined & European & Māori \\
\hline \multicolumn{7}{|l|}{ Step 1: Controls } \\
\hline Age & -0.03 & -0.08 & -0.01 & -0.10 & -0.06 & -0.14 \\
\hline Education & 0.02 & 0.14 & -0.03 & 0.04 & -0.01 & 0.02 \\
\hline Tenure & $0.15^{\star}$ & 0.17 & 0.12 & -0.09 & -0.10 & -0.03 \\
\hline Hours worked & 0.10 & 0.04 & $0.16^{*}$ & 0.01 & 0.05 & -0.03 \\
\hline$R^{2}$ change & $0.03^{\star}$ & 0.04 & $0.05^{\star}$ & 0.03 & 0.02 & 0.03 \\
\hline \multicolumn{7}{|l|}{ Step 2: Predictor } \\
\hline OBSE & $0.37 \neq$ & $0.20^{*}$ & $0.47 \ddagger$ & $-0.22 \ddagger$ & $-0.25^{\star \star}$ & $-0.21^{\star \star}$ \\
\hline$R^{2}$ change & $0.14 \ddagger$ & $0.04^{*}$ & $0.22 \ddagger$ & $0.05 \ddagger$ & $0.06^{\star * *}$ & $0.04 \ddagger$ \\
\hline Total $R^{2}$ & 0.17 & 0.08 & 0.26 & 0.07 & 0.08 & 0.07 \\
\hline Adjusted $R^{2}$ & 0.16 & 0.05 & 0.25 & 0.06 & 0.05 & 0.05 \\
\hline F statistic & $15.576 \ddagger$ & $2.785^{\star}$ & $15.849 \ddagger$ & $5.676 \ddagger$ & $2.734^{\star}$ & $3.086^{\star}$ \\
\hline
\end{tabular}

Notes. Standardised regression coefficients, all significance tests were two-tailed.

OBSE $=$ organisational-based self-esteem.

${ }^{\star} p<.05 ;{ }^{\star \star} p<.01 ;{ }^{\star \star \star} p<.001$.

To test Hypothesis 7, which considers the potential within-country differences between the two groups, Table 4 presents a comparison of $R^{2}$ change figures (from Step 2) with the influence of OBSE on outcomes. The $R^{2}$ change figure is shown as a percentage score and the differences between the two samples are shown to highlight the potential contribution of, and difference between, the samples (European or Māori) and the magnitude of this difference.

Table 4 shows that there are significant within-country differences between and within the present samples. The influence of OBSE on job outcomes was shown to be greater for Māori employees than 
Jarrod M. Haar and David Brougham

TABle 4. Influence (VARIANCE) OF OBSE to OUtComes: Comparing Within-COUNTRY RACIAL GROUPS

Variables $\quad$ European (\%) $\quad$ Māori (\%) Difference: Māori-European (\%)

\begin{tabular}{llrr}
\hline Job satisfaction & 3 & 21 & +18 \\
Organisational commitment & 5 & 23 & +18 \\
OCBs & 2 & 15 & +13 \\
Positive affect & 4 & 22 & +18 \\
Negative affect & 6 & 4 & -2
\end{tabular}

Notes. OBSE $R^{2}$ change data from Tables 2 and 3 representing the contribution OBSE makes to outcomes. OBSE = organisational-based self-esteem; OCBs = organisational citizenship behaviours.

for Europeans (an additional 13-18\%), as was its influence on positive affect (an additional 18\%). The only difference in strength for European employees is towards negative affect and the difference is minor (an additional 2\%). Overall, we argue these findings provide support for significant withincountry differences in the expected direction, with Māori reporting higher influence from OBSE.

\section{DISCUSSION}

Our results show that cultural differences can have a significant bearing on how people approach and feel about work. Culture dictates how people view relationships, and what they get out of work. However, the complexity of individual values and how they impact on causal modelling can be difficult to decipher (Homer \& Kahle, 1988). Meaningful work is important in developing this selfdetermination and well-being. Given the positive changes to Māori employment outcomes in the New Zealand workplace, it is not surprising that the present study finds that OBSE is an important predictor for the job and mood outcomes for Māori. The present study addresses an area largely missing in cross-cultural research by focusing on cultural differences within a country. New Zealand provides a setting where a stable, developed Western country with a strong and vibrant indigenous population could be explored and, for the first time, evidence was found that OBSE has a significant and distinct influence on a wide range of outcomes. Serious consideration over the generalisability of measures when focusing on large diverse populations within a country should be questioned. This paper adds further evidence to a growing body of knowledge that suggests that management needs to focus formal and informal practices toward different ethnic groups.

Overall, our analysis is consistent with international literature and showed that OBSE as a construct is stable and useful for predicting outcomes. Importantly, we found that outcomes predicted by OBSE within the combined study sample were significant and accounted for moderate amounts of variance: $-12 \%$ of variance towards most outcomes, although a more modest $5 \%$ for negative affect. However, when explored separately, we found OBSE to be a much more modest predictor of outcomes for European employees than for Māori employees, accounting for roughly 5\% of the variance of most outcomes and no significant variance towards OCBs. Conversely, for Māori employees, OBSE was an excellent predictor, accounting for much larger levels of variance (roughly 20\%). It was only in regards to negative affect that the effects for both Māori and Europeans were similar, showing OBSE to be a significant but smaller predictor of this outcome.

We suggest that the importance and greater strength of OBSE on most outcomes for Māori may relate to the importance of work for Māori. As noted earlier, Māori are over-represented in the unemployment statistics compared with Europeans and, as such, employment and its associated influence on self-esteem may be very different for Māori. Although no significant difference in levels of 
OBSE between Māori and European employees was found, the influence is obviously clear and may highlight the power that OBSE can have on Māori employees. As such, comparing levels of constructs, like those within OBSE, may be insufficient to determine effects. It was only though individually assessing the models that the true power of influence was shown.

Our findings support the need for within-country exploration of employees, as it was clear that employee OBSE influenced outcomes with greater strength (via variance accounted for) when we treated the employee samples separately rather than as a combined sample. Importantly, the employees in this study are from the same types of organisations, which highlights that these differences are not profession- or organisation-specific, but culturally specific. Our findings were similar to the significant differences in amounts of variance found in Hofstedes et al.'s (2010) study within Brazil. Overall, our findings support Riordan and Vandenberg's (1994) suggestion that differences should be treated separately rather than being lost within a cultural 'melting pot'. In the past, New Zealand has been included in large international cross-cultural studies that have compared cultural outcomes within 48 countries (Hill, Yang, Hawkins, \& Ferris, 2004) and in samples of over 129,000 employees (Huang \& Van de Vliert, 2004). Given our present findings, we question how generalisable these results may be at the within-country level of analysis, given the potential size of the variance found within our New Zealand study. It is clear that studying cultural differences within countries may have important research implications for studies of country-level constructs, since determining whether significant variation exists (as within this study) may provide insights into how dimensions such as OBSE can best be enhanced and managed for specific within-country groups.

Our paper argues the importance of considering differences between groups within a country because of the effects cultural differences have on employee outcomes, and we suggested this would be especially relevant for Māori employees. This paper's findings mirror those of Cohen (2007) and Hofstede (1983), who understood the false generalisations that come from treating a country as one homogenous culture. As noted earlier, comparing cultural differences within a country is still underresearched, and the findings that are available show some intriguing results (e.g., Cohen, 2007; Hofstede et al., 2010). While numerous factors are likely at play, this study contributes to the literature by highlighting the importance of diversity in Western countries (Fearon, 2003).

\section{Implications for managers}

In addition to indigenous populations, Western countries are becoming more diverse due to immigration and thus understanding and managing this diversity effectively is an important issue moving forward. The most recent census data shows that our Māori, Asian, and Pacific populations make up over 34\% of the population (Statistics New Zealand, 2013a), and this is expected to rise to over $40 \%$ over the next 12 years (Statistics New Zealand, 2010). HR practitioners and researchers argue that a strong business case for effectively managing diversity in workplaces exists: a sample of HR managers within New Zealand showed that diversity management was a key concern, alongside the ageing workforce (Macky, 2010). Furthermore, New Zealand research shows that an organisational climate encouraging diversity encourages employees to reciprocate with higher levels of employee commitment, job satisfaction, and trust (Houkamau \& Boxall, 2011), all of which benefit both the employee and the organisation.

This paper finds a need for tailoring culturally specific HR policies to accommodate different cultural backgrounds, which is consistent with calls from Ramamoorthy and Carroll (1998). Parallels can be draw from a number of education journals that have looked at methods to create highperformance workplaces; for example, Marie, Fergusson, and Boden (2008) suggested that tailoring culturally specific learning environments could enhance learning for Māori students. This paper demonstrates that organisations may gain enhanced benefits by building Māori employees' OBSE, 
as it was found to significantly impact on employee attitudes and behaviours that can, ultimately, enhance an organisation's performance. We suggest that HR policies tailored to fit the cultural needs of Māori may be needed in order for Māori employees to reach their full potential in the workplace; for example, encouraging managers to share positive feedback with Māori employees would build their OBSE. Foley, Linnehan, Greenhaus, and Weer (2006) found that supervisors provided more support for employees when they were racially similar. This is because support is often given to employees in similar positions as their supervisors. Given the cultural differences between Māori and Europeans (and increasing diversity in general), we suggest that training managers to understand differences in culture would be highly advantageous for all employees and organisations. This could be achieved through more training around culture, or the promotion of more Māori to supervisory positions.

\section{Limitations and future research}

The present study has several limitations consistent with the types of research methods it used; for example, problems around common-method variance, self-reported data, and the overall generalisability of findings need to be taken into account when interpreting findings. Furthermore, a larger sample of European employees would have been desirable. Several measures have been taken to reduce these effects; for example, the data was collected in two time periods (predictors then outcomes). Future studies might include researching other ethnicities within New Zealand, such as Asian and Pacific Islanders, who also make up a significant part of New Zealand's population. Another shortfall with the study was individualism/collectivism was not tested within the statistical model, the assumption being that Māori are for the most part more collectivistic than New Zealand Europeans (Harrington \& Liu, 2002; Tassell et al., 2010; Brougham \& Haar, 2013). Testing additional outcomes and different predictors might also be an important avenue to investigate. Overall, much more research is needed into contemporary Māori culture within the New Zealand workplace. This would give an insight into how culture has changed over the passage of time. It would also show how the interaction of a broad range of cultures has affected each other, not just the interaction between Māori and New Zealand European. Qualitative research could be used to tap into the rich contextual nature of these changes, and why specifically OBSE is an important predictor of outcomes.

\section{CONCLUSION}

The present study investigated the influence of cultural differences on OBSE within New Zealand by testing differences between European and Māori employees. While both groups registered similar levels of OBSE, there was much stronger influence towards outcomes for the Māori group. Indeed, the strength of these differences provides a useful insight into the potential within-country differences and improves our understanding of cross-cultural studies. Of particular importance is that researchers need to consider the ethnic make up of each country sample and at least capture this data to allow for an initial level of analysis to be explored. Although large combined samples provide powerful insight, we suggest that failing to capture and test for within-country differences may misdirect research agendas. Finally, we advocate for the tailoring of formal and informal approaches to get the best out of diverse workplaces.

\section{ACKNOWLEDGEMENT}

The project was funding with a Marsden Grant (Contract Number X957). 


\section{References}

Aryee, S., \& Luk, V. (1996). Work and non-work influences on the career satisfaction of dual-earner couples. Journal of Vocational Behavior, 49, 38-52.

Bowling, N. A., Eschleman, K. J., Wang, Q., Kirkendall, C., \& Alarcon, G. (2010). A meta-analysis of the predictors and consequences of organization-based self-esteem. Journal of Occupational and Organizational Psychology, 83, 601-626.

Brougham, D., \& Haar, J. M. (2013). Collectivism, cultural identity and employee mental health: A study of New Zealand Māori. Social Indicators Research, 114, 1143-1160.

Chan, S. C., Huang, X., Snape, E., \& Lam, C. K. (2013). The janus face of paternalistic leaders: Authoritarianism, benevolence, subordinates' organization-based self-esteem, and performance. Journal of Organizational Behavior, 34 , $108-128$.

Chen, Z. X., Aryee, S., \& Lee, C. (2005). Test of a mediation model of perceived organizational support. Journal of Vocational Behavior, 66, 457-470.

Cohen, A. (1999). The relation between commitment forms and work outcomes in jewish and Arab culture. Journal of Vocational Behavior, 54, 371-391.

Cohen, A. (2006). The relationship between multiple commitments and organizational citizenship behavior in Arab and jewish culture. Journal of Vocational Behavior, 69, 105-118.

Cohen, A. (2007). One nation, many cultures: A cross-cultural study of the relationship between personal cultural values and commitment in the workplace to in-role performance and organizational citizenship behavior. Cross-Cultural Research, 41, 273-300.

Cohen, A., \& Kirchmeyer, C. (2005). A cross cultural study of the work/nonwork interface among israeli nurses. Applied Psychology: An International Review, 54, 537-567.

Durie, M. (2003). Ngā kāhui pou launching Māori futures. Wellington, New Zealand: Huia Publishers.

Elfenbein, H. A., \& Ambady, N. (2002). On the universality and cultural specificity of emotion recognition: A meta-analysis. Psychological Bulletin, 128(2), 203.

Erez, M., \& Gati, E. (2004). A dynamic, multi-level model of culture: From the micro level of the individual to the macro level of a global culture. Applied Psychology: An International Review, 53, 583-598.

Fearon, J. D. (2003). Ethnic and cultural diversity by country. Journal of Economic Growth, 8, 195-222.

Ferris, D. L., Lian, H., Brown, D. J., \& Morrison, R. (2015). Ostracism, self-esteem, and job performance: When do we self-verify and when do we self-enhance? Academy of Management Journal, 58, 279-297.

Foley, S., Linnehan, F., Greenhaus, J. H., \& Weer, C. H. (2006). The impact of gender similarity, racial similarity, and work culture on family-supportive supervision. Group \& Organization Management, 31, 420-441.

Gardner, D. G., \& Pierce, J. L. (2001). Self-esteem and self-efficacy within the organizational context: A replication. Journal of Management Systems, 13, 31-48.

Gardner, D. G., Van Dyne, L., \& Pierce, J. L. (2004). The effects of pay level on organization-based self-esteem and performance: A field study. Journal of Occupational and Organizational Psychology, 77, 307-322.

Haar, J., \& Brougham, D. (2011). Outcomes of cultural satisfaction at work: A study of New Zealand Maori. Asia Pacific Journal of Human Resources, 49(4), 461-475.

Haar, J. M., \& Brougham, D. (2013). An indigenous model of career satisfaction: Exploring the role of workplace cultural wellbeing. Social Indicators Research, 110, 873-890.

Harrington, L., \& Liu, J. H. (2002). Self-enhancement and attitudes toward high achievers: A bicultural view of the independent and interdependent self. Journal of Cross-Cultural Psychology, 33, 37-55.

Hartung, P., Fouad, N., Leong, F., \& Hardin, E. (2010). Individualism-collectivism: Links to occupational plans and work values. Journal of Career Assessment, 18, 34-45.

Heck, A. K., Bedeian, A. G., \& Day, D. V. (2005). Mountains out of molehills? Tests of the mediating effects of self-esteem in predicting work place complaining. Journal of Applied Social Psychology, 35, 2262-2289.

Hill, E., Yang, C., Hawkins, A., \& Ferris, M. (2004). A cross-cultural test of the work-family interface in 48 countries. Journal of Marriage and the Family, 66(5), 1300-1316.

Hofstede, G. (1983). The cultural relativity of organizational practices and theories. Journal of International Business Studies, 14, 75-89.

Hofstede, G., Garibaldi de Hilal, A., Malvezzi, S., Tanure, B., \& Vinken, H. (2010). Comparing regional cultures within a country: Lessons from Brazil. Journal of Cross-Cultural Psychology, 41, 336-352. 
Hofstede, G. H. (1980). Culture's consequences: International differences in work-related values. Beverly Hills, CA: Sage. Homer, P., \& Kahle, L. (1988). A structural equation test of the value-attitude-behavior hierarchy. Journal of Personality and Social Psychology, 54, 638-646.

Hook, G. (2007). A future for Māori education part II: The reintegration of culture and education. MAI Review, 1, 1-17.

Houkamau, C., \& Boxall, P. (2011). The incidence and impacts of diversity management: A survey of New Zealand employees. Asia Pacific Journal of Human Resources, 49, 440-460.

Huang, X., \& Van de Vliert, E. (2004). Job level and national culture as joint roots of job satisfaction. Applied Psychology: An International Review, 53, 329-348.

Judge, T. A., \& Bono, J. E. (2001). Relationship of core self-evaluation traits - self-esteem, generalized self-efficacy, locus of control, and emotional stability - with job satisfaction and job performance: A meta-analysis. Journal of Applied Psychology, 86, 80-92.

Judge, T. A., Bono, J. E., Erez, A., \& Locke, E. A. (2005). Core self-evaluations and job and life satisfaction: The role of self-concordance and goal attainment. Journal of Applied Psychology, 90, 257-268.

King, M. (2003). The penguin history of New Zealand. Auckland, New Zealand: Penguin Books.

Lapointe, É., Vandenberghe, C., \& Panaccio, A. (2011). Organizational commitment, organization-based self-esteem, emotional exhaustion and turnover: A conservation of resources perspective. Human Relations, 64, 1609-1631.

Lee, J. (2003). An analysis of the antecedents of organization-based self-esteem in two Korean banks. International Journal of Human Resource Management, 14, 1046-1066.

Lee, K., \& Allen, N. J. (2002). Organizational citizenship behavior and workplace deviance: The role of affect and cognitions. Journal of Applied Psychology, 87, 131-142.

Lee, S.-L., Chiu, C.-Y., \& Chan, T.-K. (2005). Some boundary conditions of the expressor culture effect in emotion recognition: Evidence from Hong Kong Chinese perceivers. Asian Journal of Social Psychology, 8(3), 224-243. doi: 10.1111/j.1467-839X.2005.00169.x.

Liu, J., Hui, C., Lee, C., \& Chen, Z. X. (2013). Why do I feel valued and why do I contribute? A relational approach to employee's organization-based self-esteem and job performance. Journal of Management Studies, 50, 1018-1040.

Lo, K. D., \& Houkamau, C. (2012). Exploring the cultural origins of differences in time orientation between European New Zealanders and Māori. New Zealand Journal of Human Resource Management, 12, 105-123.

Macky, K. (2010). An overview of HRM research needs in NZ: What do practitioners and academics say and how do we take this forward. HRINZ Research Forum, University of Auckland-Business School, University of Auckland, Auckland, NewZealand.

Marie, D., Fergusson, D. M., \& Boden, J. M. (2008). Educational achievement in Māori: The roles of cultural identity and social disadvantage. Australian Journal of Education, 52, 183-196.

Meyer, J. P., Allen, N. J., \& Smith, C. A. (1993). Commitment to organizations and occupations: Extension and test of a three-component conceptualization. Journal of Applied Psychology, 78, 538-551.

Mueller, C. W., Finley, A., Iverson, R. D., \& Price, J. L. (1999). The effects of group racial composition on job satisfaction, organizational commitment, and career commitment. Work and Occupations, 26, 187-219.

Organ, D. W. (1988). Organizational citizenship behavior: The good Soldier syndrome. Lexington, MA: Lexington Books.

Pierce, J. L., \& Gardner, D. G. (2004). Self-esteem within the work and organizational context: A review of the organization-based self-esteem literature. Journal of Management, 30, 591-622.

Pierce, J. L., Gardner, D. G., Cummings, L. L., \& Dunham, R. B. (1989). Organization-based self-esteem: Construct definition measurement and validation. Academy of Management Journal, 32, 622-648.

Podsakoff, P, M., MacKenzie, S. B., Paine, J. B., \& Bachrach, D. G. (2000). Organizational citizenship behaviors: A critical review of the theoretical and empirical literature and suggestions for future research. Journal of Management, 26, 513-563.

Podsiadlowski, A., \& Fox, S. (2011). Collectivist value orientations among four ethnic groups: Collectivism in the New Zealand context. New Zealand Journal of Psychology, 40, 5-18.

Price, J. L. (1997). Handbook of organizational measurement. International Journal of Man Power, 18, 303-558.

Ramamoorthy, N., \& Carroll, S. (1998). Individualism/collectivism orientations and reactions toward alternative human resource management practices. Human Relations, 51, 571-588.

Riordan, C. M., \& Vandenberg, R. J. (1994). A central question in cross-cultural research: Do employees of different cultures interpret work-related measures in an equivalent manner? Journal of Management, 20, 643-671. 
Riordan, C. M., Weatherly, E.W., Vandenberg, R. J., \& Self, R. M. (2001). The effects of pre-entry experiences and socialization tactics on newcomer attitudes and turnover. Journal of Managerial Issues, 13, 159-177.

Sedikides, C., Gaertner, L., \& Toguchi, Y. (2003). Pancultural: Self-enhancement. Journal of Personality and Social Psychology, 84, 60-97.

Smith, C. A., Organ, D. W., \& Near, J. P. (1983). Organizational citizenship behavior: Its nature and antecedents. Journal of Applied Psychology, 68, 653-663.

Spector, P., Cooper, C., Poelmans, S., Allen, T., O’Driscoll, M., Sanchez, J., \& ... Lu, L. (2004). A cross-national comparative study of work-family stressors, working hours, and well-being: China and Latin America versus the Anglo world. Personnel Psychology, 57, 119-142.

Spector, P, E., Allen, T. D., Poelmans, S., Lapierre, L., Cooper, C., O'Driscoll, M., et al. (2007). Cross-national differences in relationships of work demands, job satisfaction, and turnover intentions with work-family conflict. Personnel Psychology, 60, 805-835.

Statistics New Zealand (2007). QuickStats about incomes. Wellington, New Zealand: New Zealand Government.

Statistics New Zealand (2010). National ethnic population projections: 2006 (base)-2026 update. Wellington, New Zealand: New Zealand Government.

Statistics New Zealand (2013a). 2013 Census quickstats about national highlights. Wellington, New Zealand: New Zealand Government.

Statistics New Zealand (2013b). Introducing ethnic labour force statistics by age: June 2013 quarter. Wellington, New Zealand: New Zealand Government.

Tang, T. L., Davis, G. M., Dolinski, D., Ibrahim, A. H. S., Sutarso, T., Wagner, S. L., \& Tang, T. (2002). Money attitude, organization-based self-esteem, public other-serving and private self-serving motives, and OCB-altruism: The USA, Taiwan, Poland, and Egypt. Academy of Management Conference, Denver, Colorado.

Tang, T. L., \& Ibrahim, A. H. S. (1998). Antecedents of organizational citizenship behavior revisited: Public personnel in the United States and in the middle east. Public Personnel Management, 27, 529-549.

Tassell, N. A., Flett, R. A., \& Gavala, J. R. (2010). Individualism/collectivism and academic self-enhancement in New Zealand Māori university students. Journal of Pacific Rim Psychology, 4, 138-151.

Te Puni, Kōkiri. (2009). Māori employment by occupation. Wellington: Te Puni Kōkiri (Ministry of Māori Development).

Te Puni, Kōkiri. (2012). He Kai Kei Aku Ringa - The crown-māori economic growth partnership-action plan 2012-2017. Wellington, New Zealand: Te Puni Kōkiri.

Van Dyne, L., \& Pierce, J. L. (2004). Psychological ownership and feelings of possession: Three field studies predicting employee attitudes and organizational citizenship behavior. Journal of Organizational Behavior, 25, 439-459.

Warr, P., Barter, J., \& Brownbridge, G. (1983). On the independence of positive and negative affect. Journal of Personality and Social Psychology, 44, 644-651.

Watson, D., \& Clarke, L. A. (1988). Positive and negative affectivity and their relation to anxiety and depressive disorders. Journal of Abnormal Psychology, 97, 346-353.

Watson, D., Clark, L. A., \& Tellegen, A. (1988). Development and validation of brief measures of positive and negative affect: The PANAS scale. Journal of Personality and Social Psychology, 54, 1063-1070.

Wheeler, L., Reis, H. T., \& Bond, M. H. (1989). Collectivism-individualism in everyday social life: The middle kingdom and the melting pot. Journal of personality and social psychology, 57, 79-86. 